\title{
Visual defects in children of low birthweight
}

\author{
EVA ALBERMAN, JULIA BENSON, AND STEPHEN EVANS \\ Department of Clinical Epidemiology, London Hospital Medical College
}

SUMMARY The prevalence of visual defects at ages 7 to 9 in 1485 children of birthweight $2000 \mathrm{~g}$ or less is reported. These children were born in 1970, 1971, and 1973 to parents resident in what is now the South East Thames Regional Health Authority area, and comprise $73.9 \%$ of all survivors of births of this weight, and $81 \%$ of those whose present address is known. Only $16(1 \%)$ children were reported to have serious visual defects; 5 had retrolental fibroplasia. For the children attending normal schools there was a significant excess of both mild and more severe visual defects compared with matched controls. A distant visual acuity of $6 / 6$ was reported in the better eye of $89 \%$, and in both eyes of $83 \%$ of the low birthweight group.

It has long been known that babies of low birthweight are more likely than average to suffer from visual defects. Although retrolental fibroplasia is the defect most closely associated with prematurity, other visual defects have been reported in such babies, including myopia and cataracts in those who were small-for-dates. ${ }^{1}$

A follow-up study of infants weighing $2000 \mathrm{~g}$ or less at birth and born in 1970, 1971, or 1973 to mothers resident in the South East Thames Regional Health Authority area gave an opportunity to measure prevalence of visual impairment in the survivors and, for children at normal schools, to compare visual acuity with that of controls.

\section{Subjects and methods}

Sample and controls. The sample was derived from children born in 1970,1971 , or 1973 to mothers resident in the districts that were included in the South East Thames Regional Health Authority area created in 1974. Birth notifications and maternity registers for the relevant years were scanned in 1974, and infants weighing $2000 \mathrm{~g}$ or less at birth were chosen for study. Available birth data included place of birth, birthweight, and gestational age. Results from this study have been reported previously. ${ }^{2} 3$

When the surviving children were aged 7 to 9 , members of the research team were allowed to abstract health data from school medical records of those still resident in the region. The survival and tracing rates of the study children are given in the Figure. A log-linear model analysis was carried out to test whether the success rate of tracing the surviving children varied between groups of different birthweights or between different gestational ages. This showed no significant differences for children for whom the birthweight and gestational age were known, but for the $1.4 \%$ children for whom the exact birthweight was not known (although they were reported as being under $2000 \mathrm{~g}$ ), or for the $8.9 \%$ children whose gestational age was not known, the tracing rate was significantly lower.

For children in normal schools a control in the same class, matched for gender and age was chosen, and similar health data abstracted. No information about birthweight was generally available in the school record, so it had to be assumed that the weight of the controls was typical of all births, except that all births of $2000 \mathrm{~g}$ or less that had occurred in the region would have been allocated to our study group. For children not in normal schools handicap registers in the region were scanned particularly for evidence of sensory or neurological defect, malformation, or non-accidental injury. Information was sought from the appropriate area specialist in community medicine (child health) for children reported to be living in Britain but outside the region.

Data on vision. The data available on the visual function of these children were of two kinds. Firstly, any recorded comments relating to visual defects were noted. Secondly, results of tests of unaided distant visual acuity were recorded. These had been administered as part of the routine school medical examination, and without any knowledge of our subsequent study. 


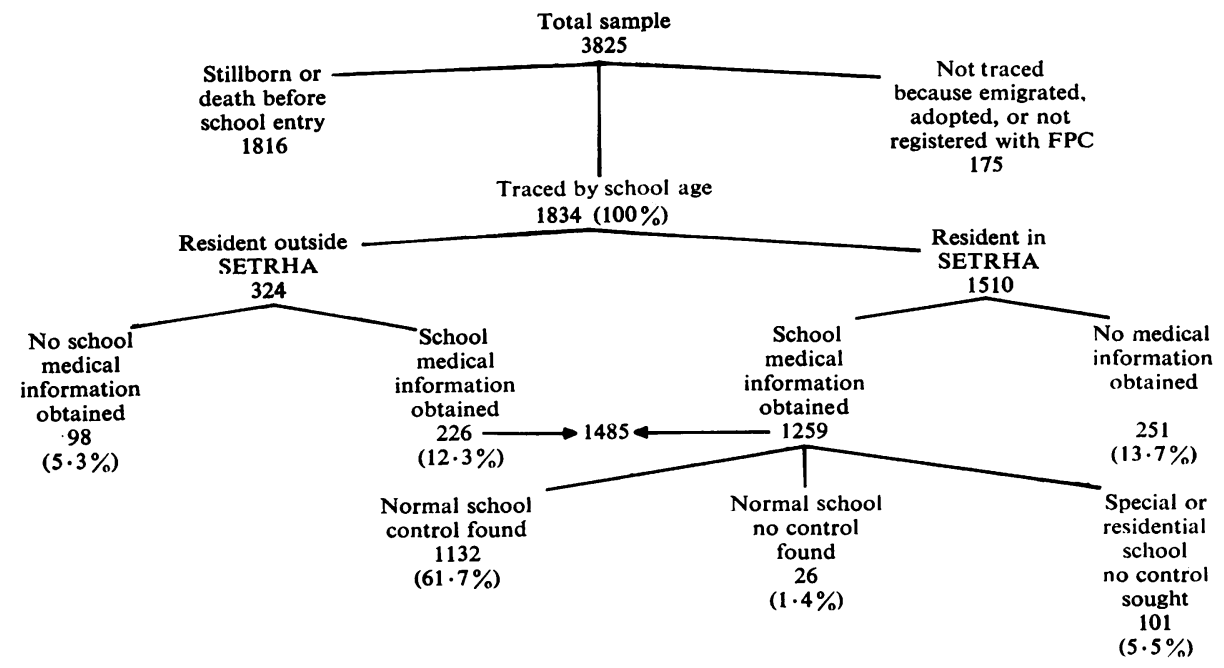

FPC $=$ Family Practitioner Committee, SETRHA = South East Thames Regional Health Authority

Figure Numbers in total sample and percentage of those traced with and without medical information.

Although there was no external validation of these tests, children in normal schools and their matched controls would mainly have been examined by the same medical staff. We had reports of school medical examinations for 1485 study children (Figure) including results of visual acuity tests for 1368. Matching controls were found for $1132(89.9 \%)$ of the 1259 children with medical records still resident in the South East Thames Regional Health Authority area, and results of visual acuity were available for all but 49 of the cases and 23 of the controls.

\section{Results}

Serious visual defects reported in the children of low birthweight. A list of children with serious defects of the eyes derived from the 1485 children in the sample for whom medical information was available is shown in Table 1. In one additional child the defect was attributable to postnatal causes, and that was the loss of an eye owing to a gun-shot injury. One other child, not included in the 1485 , was reported to have bilateral cataracts at birth but was subsequently not traced.

Retrolental fibroplasia. There were 5 children among the 1485 described as suffering from retrolental fibroplasia. None had a gestational age of more than 29 weeks and their birthweights ranged from 936 to $1440 \mathrm{~g}$. None of these had been admitted to the one nursery in the region offering intensive care at the time. In the sample of 1485 with school information the rate of retrolental fibroplasia decreased from $4.3 \%$ in those weighing $1000 \mathrm{~g}$ or less, to $1.3 \%$ in those weighing between 1001 and $1500 \mathrm{~g}$. All, except one who was registered as partially sighted, were registered blind, and all were attending special schools.

Optic atrophy. Four children were described as having optic atrophy, all had associated cerebral palsy, and all were severely handicapped.

Cataracts. Three children out of the 1485 were reported as having cataracts and, as described earlier, a further, untraced, child had been so described at birth. Each had a gestational age of at least 36 weeks, and birthweights ranged from 1740 to $1946 \mathrm{~g}$. One had Down's syndrome and one was thought to have contracted intrauterine rubella. No aetiology was suggested for the other two.

Other defects. The remaining children with severe visual defects comprised 2 with perceptual problems, a child with severe myopia, and another with nystagmus.

Taking all these defects together, the rate among the survivors with medical information was $4.3 \%$ of birthweight of $1000 \mathrm{~g}$ or less; $3.3 \%$ in those between 1001 and $1500 \mathrm{~g}$ birthweight and 32 weeks' or less gestation; $2.9 \%$ of the same birthweight but of at least 33 weeks' gestation; and $0.9 \%, 0.2 \%$, and $1.6 \%$ in those weighing 1501 to $2000 \mathrm{~g}$, but under 33,33 to 36 , and at least 37 weeks of gestation respectively. 
Table 1 Clinical description of children with severe visual defects

\begin{tabular}{|c|c|c|c|c|c|}
\hline & & $\begin{array}{l}\text { Birthweight } \\
(g)\end{array}$ & $\begin{array}{l}\text { Gestation } \\
\text { (weeks) }\end{array}$ & Schooling & $\begin{array}{l}\text { Visual acuity tested } \\
\text { (one eye } \times \text { other eye) }\end{array}$ \\
\hline \multicolumn{6}{|c|}{ Retrolental fibroplasia } \\
\hline 1 & $\mathrm{ESN}(\mathrm{S})$ & 936 & 26 & Residential & No $\times$ no \\
\hline 2 & Average IQ & 1440 & 29 & $\begin{array}{l}\text { Special unit waiting } \\
\text { for special school }\end{array}$ & No $\times 6 / 60$ \\
\hline 3 & $\begin{array}{l}\text { RLF one eye, myopia in other, hearing aid, mental } \\
\text { handicap. Has had severe postnatal illnesses }\end{array}$ & 1425 & 28 & Residential & No $\times$ no \\
\hline 4 & Spastic diplegia and ventricular septal defect & 1072 & 29 & Residential & No $\times$ no \\
\hline 5 & Bilateral corneal opacities and RLF & 1380 & 29 & Special & No $\times$ no \\
\hline \multicolumn{6}{|c|}{ Optic atrophy } \\
\hline & $\begin{array}{l}\text { L hemiplegia, arrested hydrocephalus, } L \text { eye blind, } \\
\text { some vision on } R \text {, registered blind }\end{array}$ & 1425 & 32 & Normal & No $\times 6 / 12-36$ \\
\hline 2 & Athetoid, ESN(S) & 1232 & 34 & Special & No $\times$ no \\
\hline 3 & $\begin{array}{l}\text { Bilateral pigmentary retinopathy, spastic diplegia, } \\
\text { registered partially sighted, ESN(S) }\end{array}$ & 1470 & 41 & Special & No $\times$ no \\
\hline 4 & $\begin{array}{l}\text { Severe dystonic quadriplegia, epilepsy, near vision, } \\
\text { large objects only, ESN(?S) }\end{array}$ & 1965 & 37 & Residential & No $\times$ no \\
\hline \multicolumn{6}{|c|}{ Cataracts } \\
\hline 1 & Cataracts reported at birth, not traced & 1740 & 36 & $?$ & No $\times$ no \\
\hline 2 & ?Rubella syndrome - severe bilateral hearing loss & & & & \\
\hline & $\mathrm{R}$ cataract, microphthalmia & 1825 & 38 & Normal & $6 / 12 \times 6 / 12$ \\
\hline 3 & Down's syndrome - cataracts needled, severe myopia & 1851 & 39 & Residential & No $\times$ no \\
\hline 4 & L eye cataract-operated, behind in school & 1946 & 40 & Normal & No $\times$ no \\
\hline \multicolumn{6}{|c|}{ Other } \\
\hline 1 & Perceptual problems, borderline ESN(M) & 1437 & 32 & Special & $6 / 20 \times 6 / 20$ \\
\hline 2 & $\begin{array}{l}\text { 'Special visual perceptual difficulty', IQ } 80 \text {, } \\
\text { developmental delay }\end{array}$ & & & & \\
\hline 3 & $\begin{array}{l}\text { developmental delay } \\
\text { Nystagmus, registered blind }\end{array}$ & $\begin{array}{l}1730 \\
1420\end{array}$ & $\begin{array}{l}38 \\
36\end{array}$ & $\begin{array}{l}\text { Normal } \\
\text { Special }\end{array}$ & $6 / 12 \times 6 / 12$ \\
\hline 4 & Myopia, spastic diplegia, special school, IQ 65-74 & 1946 & 32 & Residential & $6 / 60 \times 6 / 24$ \\
\hline
\end{tabular}

\section{Visual acuity in the cases and controls.}

\section{Completeness of testing}

For $4.2 \%$ of the controlled cases, $2 \%$ of the controls, and $19.3 \%$ of all uncontrolled cases for whom any medical information was available, no data on visual acuity were recorded, nor was there any suggestion in the records of the presence of a visual defect. The higher proportion with unknown visual function in the uncontrolled cases reflects the fact that they include firstly all the children in special schools, and secondly those resident outside the South East Thames Regional Health Authority area for whom medical information was altogether less complete, since it was not abstracted by the survey team. The difference between the proportions not tested in cases and controls is statistically significant $(P<0.001)$ and will be described further below.

\section{Levels of visual acuity}

The tests of visual acuity available were carried out as part of the routine school medical examinations so that these were not standardised or validated. The results of the tests of the controls were compared with those obtained from the National Child Development Study in 1965 when the children in that study were aged 7 years. ${ }^{4}$ In the earlier study $87 \%$ of the children tested had an acuity of $6 / 6$ in their better eye, and $79 \%$ had an acuity of $6 / 6$ in both eyes, but this was true of $94 \%$ and $89 \%$ respectively of the controls in the present study. Factors accounting for this difference may be a? different age at testing, less rigorous testing, the fact that only children in normal schools were included in this later study, or even possibly a change over the years. The corresponding proportions in the low birthweight cases in the present study are $89 \%$ and $83 \%$.

A more valid comparison is one between casecontrol pairs who were matched for school and class, and therefore were largely tested by the same medical staff, and at the same time. The comparison of case-control pairs is based on the ratio of the numbers of pairs who are discordant for the factor under consideration, ${ }^{5}$ which gives an estimate of relative risk.

Tables 2 and 3 show the case-control data derived from 1132 pairs, comparing the frequency of discordance between the pairs in respect of vision in the better eye or in both eyes of $6 / 6$. The tables also show the numbers of pairs in which neither eye or only one was tested. The relative risk in cases and controls is estimated as follows. The relative risk of a low birthweight survivor compared with a matched control having a visual acuity of less than $6 / 6$ in the better eye is 100: $54=1.85\left(\chi^{2}=13 \cdot 15\right.$; $P<0.001)$. Similarly the relative risk of having a visual acuity of less than $6 / 6$ in both eyes is 154 : 
Table 2 Vision in better eye: 1132 case-control pairs

\begin{tabular}{|c|c|c|c|}
\hline \multirow[t]{2}{*}{ Cases } & \multicolumn{3}{|c|}{ Controls } \\
\hline & $6 / 6$ & $\begin{array}{l}\text { Worse than } \\
6 / 6\end{array}$ & $\begin{array}{l}\text { Neither eye } \\
\text { tested }\end{array}$ \\
\hline $\begin{array}{l}6 / 6 \\
\text { Worse than } 6 / 6 \\
\text { Neither eye tested }\end{array}$ & $\begin{array}{l}900 \\
100 \\
42\end{array}$ & $\begin{array}{r}54 \\
12 \\
1\end{array}$ & $\begin{array}{r}17 \\
0 \\
6\end{array}$ \\
\hline
\end{tabular}

Table 3 Vision in both eyes: 1132 case control pairs

\begin{tabular}{|c|c|c|c|}
\hline \multirow[t]{2}{*}{ Cases } & \multicolumn{3}{|c|}{ Controls } \\
\hline & $\begin{array}{l}6 / 6 \\
\text { both }\end{array}$ & $\begin{array}{l}\text { Either worse } \\
\text { than } 6 / 6\end{array}$ & $\begin{array}{l}\text { One or both } \\
\text { eyes not tested }\end{array}$ \\
\hline \multirow{3}{*}{$\begin{array}{l}6 / 6 \text { both } \\
\text { Either worse than } 6 / 6 \\
\text { One or both eyes not } \\
\text { tested }\end{array}$} & 787 & 91 & 16 \\
\hline & 154 & 30 & 3 \\
\hline & 41 & 3 & 7 \\
\hline
\end{tabular}

$91=1.69\left(\chi^{2}=15.69 ; P<0.001\right)$. The relative risk of the low birthweight survivors not having both eyes tested is $43: 17=2.5 \quad\left(\chi^{2}=10.42\right.$; $P<0.01)$ and of having only one eye tested 44: $19=2 \cdot 3\left(\chi^{2}=9 \cdot 1 ; P<0 \cdot 01\right)$.

The same exercise can be repeated for low birthweight survivors of different birthweight or gestational age groups (Table 4). This shows that the relative risk of the better or both eyes being worse than $6 / 6$ declines consistently with increasing birthweight although it is always greater than one. There is a U-shaped pattern with a relative risk of nearly one in those babies of $2000 \mathrm{~g}$ or less but a gestational age of 33 to 35 weeks, and a raised risk in those with a lower or higher gestational age. However, there is no statistically significant difference (using logistic regression) in ratio of visual defects in the cases and their controls across either birthweight or gestational age, although there is a

Table 4 Relative risk of the visual acuity of the better eye being worse than $6 / 6$ by birthweight and gestation. Ratio discordant cases to controls (numbers in brackets)

\begin{tabular}{llllll}
\hline Birthweight $(g)$ & \multicolumn{2}{c}{ Weeks' gestation } & $\begin{array}{c}\text { Not } \\
\text { known }\end{array}$ & All \\
\cline { 2 - 5 } & $\leqslant 32$ & -35 & $35+$ & & \\
\hline $\begin{array}{l}\text { S1000 ratio } \\
\text { Relative risk }\end{array}$ & $(5 / 0)$ & $(0 / 0)$ & $(0 / 0)$ & $(0 / 0)$ & $(5 / 0)$ \\
$\chi^{2}$ & - & - & - & - & - \\
-1500 ratio & $(20 / 5)$ & $(3 / 1)$ & $(1 / 1)$ & $(2 / 3)$ & $(26 / 10)$ \\
Relative risk & 4 & 3 & 1 & $0 \cdot 67$ & $2 \cdot 6$ \\
$\chi^{2}$ & $7 \cdot 84$ & $0 \cdot 25$ & $0 \cdot 5$ & $0 \cdot 8$ & $6 \cdot 25$ \\
2000 ratio & $(14 / 6)$ & $(20 / 18)$ & $(33 / 16)$ & $(2 / 4)$ & $(69 / 44)$ \\
Relative risk & $2 \cdot 3$ & $1 \cdot 1$ & $2 \cdot 1$ & $0 \cdot 5$ & $1 \cdot 6$ \\
$\chi^{2}$ & $2 \cdot 45$ & $0 \cdot 11$ & $5 \cdot 22$ & $1 \cdot 5$ & $5 \cdot 10$ \\
All ratio & $(39 / 11)$ & $(23 / 19)$ & $(34 / 17)$ & $(4 / 7)$ & $(100 / 54)$ \\
Relative risk & $3 \cdot 5$ & $1 \cdot 2$ & $2 \cdot 0$ & 0.6 & $1 \cdot 85$ \\
$\chi^{2}$ & $14 \cdot 58$ & $0 \cdot 21$ & $5 \cdot 02$ & $1 \cdot 45$ & $13 \cdot 15$ \\
\hline
\end{tabular}

Table 5 Distribution of visual acuity of each eye in 1132 controlled cases and their controls

\begin{tabular}{|c|c|c|c|c|}
\hline \multirow{2}{*}{$\begin{array}{l}\text { Visual acuity of one } \\
\text { eye by the other }\end{array}$} & \multicolumn{2}{|l|}{ Cases } & \multicolumn{2}{|c|}{ Controls } \\
\hline & No & $\%^{*}$ & No & $\%^{*}$ \\
\hline $\begin{array}{l}6 / 6 \times 6 / 6 \\
6 / 6 \times 6 / 9 \\
6 / 9 \times 6 / 9 \\
6 / 6 \times 6 / 12-36 \\
6 / 9 \times 6 / 12-36 \\
6 / 12-36 \times 6 / 12-36 \\
6 / 6-9 \times 6 / 60 \\
6 / 6-9 \times \text { not known } \\
6 / 12-36 \times \text { not known } \\
\text { Not known } \times \text { not known }\end{array}$ & $\begin{array}{r}894 \\
51 \\
53 \\
23 \\
23 \\
33 \\
4 \\
1 \\
1 \\
49\end{array}$ & $\begin{array}{c}82 \cdot 5 \\
4 \cdot 7 \\
4 \cdot 9 \\
2 \cdot 1 \\
2 \cdot 1 \\
3 \cdot 1 \\
0 \cdot 4 \\
0 \cdot 09 \\
0 \cdot 09\end{array}$ & $\begin{array}{r}982 \\
36 \\
34 \\
21 \\
14 \\
18 \\
1 \\
3 \\
23\end{array}$ & $\begin{array}{c}88 \cdot 5 \\
3 \cdot 2 \\
3 \cdot 1 \\
1 \cdot 9 \\
1 \cdot 3 \\
1 \cdot 6 \\
0 \cdot 09 \\
0 \cdot 3 \\
-\end{array}$ \\
\hline Total known & 1083 & $100 \cdot 0$ & 1109 & 100 \\
\hline
\end{tabular}

*Excluding those not known.

tendency for the effect to vary more with gestation than weight.

Table 5 shows that the excess of visual defects in the study children were accounted for both by mild, and the more severe defects.

\section{Discussion}

Perhaps the most important finding in this study is the continuing presence of retrolental fibroplasia among survivors of extreme immaturity, albeit reduced considerably from the levels described in the $1950 \mathrm{~s}^{3}$ Others have commented on this, which is due jointly to a persisting fairly high risk at birth, and the remarkable increase in survival of infants of very low birthweight or gestational age. ${ }^{67}$ The prevention of this seriously handicapping disorder calls for both expertise and excellent equipment for the treatment of extreme immaturity, and indeed in the smallest babies the problem may still remain unresolved.

The problems of optic atrophy, and perceptuomotor difficulties are probably directly related to the risk of brain damage, either from asphyxia or cerebral haemorrhage, or secondary to hydrocephalus. Some of these complications also may be in part preventable with expert care.

Cataracts have been previously described in small-for-dates babies born between 1950 and 1953. ${ }^{1}$ The reason for the disease is unknown, although cataracts are commonly associated with a generalised fetal abnormality of infective or genetic origin. In the present study there were no cataracts reported in the 903 survivors with school medical records who had weighed $4 \mathrm{lb}(1814 \mathrm{~g})$ or less. This contrasts with McDonald's study in which 11 children with cataracts had been reported in 1081 children of 7 or 8 years. This may be partly accounted for by the fact that the children in McDonald's study had had ophthalmological examinations at age 6 months. 
However, the large difference does suggest there may have been a real reduction in prevalence between the two periods.

Finally a very interesting aspect of the present study was the distribution of visual acuity in children of low birthweight and attending normal schools compared with controls. The important fact to stress is that the difference was not particularly large. As many as $83 \%$ of the low birthweight group had a visual acuity of $6 / 6$ in both eyes, and $89 \%$ had a visual acuity of $6 / 6$ in the better eye. Nevertheless there was a sharp increase in the proportion with visual defects with decreasing birthweight and gestation, except in the small-for-dates survivors who showed a small rise with gestational age. These changes may reflect the existence of the mildest forms of changes characteristic of retrolental fibroplasia on the one hand and of cataracts on the other. The important lesson to be drawn is that low birthweight is associated with an excess of mildly as well as severely handicapping disorders.

Finally, it is unfortunate that the school medical records of low birthweight children should be less complete than those of controls, with twice as many without information on visual ability. Equally, the difficulty experienced in tracing the low birthweight children reflects administrative failure of the child health services in a very high risk group. These difficulties were certainly made worse by the upheaval after reorganisation in 1974. We must make sure that the effectiveness of surveillance of children's health does not deteriorate further after yet another administrative change in 1982.

We thank the many paediatricians, community physicians, clinical medical officers, school nurses, and local authority clerical officers in SETRHA without whose collaboration the 1970 s study could not have been carried out; Miss Maureen Elliott and Mrs M Egan, Paediatric Research Unit, Guy's Hospital Medical School, for help with the collection of data; Lech Jankowski and David Harrison for help with data processing; Dr Alan Mushin for assistance; the Office of Population Censuses and Surveys collaborated with this study, generously providing help with the tracing of the children.

The study was supported by a grant from the Department of Health and Social Security.

\section{References}

1 McDonald A. Children of very low birthweight. London: Spastics Society/Heinemann, 1980.

2 Stanley F J, Alberman E D. Infants of very low birthweight. I. Perinatal factors affecting survival: II. Perinatal factors in and conditions associated with respiratory distress syndrome. Dev Med Child Neurol 1979; 20: 300-22.

3 Alberman E, Benson J, McDonald A. Cerebral palsy and severe educational subnormality in low-birthweight children: a comparison of births in 1951-53 and 1970-73. Lancet 1982; i: 606-8.

4 Alberman E D, Butler N R, Sheridan M D. Visual acuity of a national sample (1958 cohort) at 7 years. Dev Med Child Neurol 1971 ; 13: 9-14.

5 Mantel N, Haenszel W. Statistical aspects of the analysis of data from retrospective studies of disease. JNCI 1959; 22: 719-48.

- Hey E. Retrolental fibroplasia as one index of perinatally acquired handicap. In: Chalmers I, Mcllwaine G, eds. Perinatal audit and surveillance. Proceedings of the Eighth Study Group of the Royal College of Obstetricians and Gynaecologists. London: Royal College of Obstetricians and Gynaecologists, 1980: 188-97.

7 Phelps D L. Letter: Vision loss due to retinopathy of prematurity. Lancet 1981 ; i: 606.

Correspondence to Professor E Alberman, Department of Clinical Epidemiology, London Hospital Medical College, Turner Street, London E1 2AD.

Received 9 June 1982 